Edited by Allan Beveridge, Femi Oyebode and Rosalind Ramsay

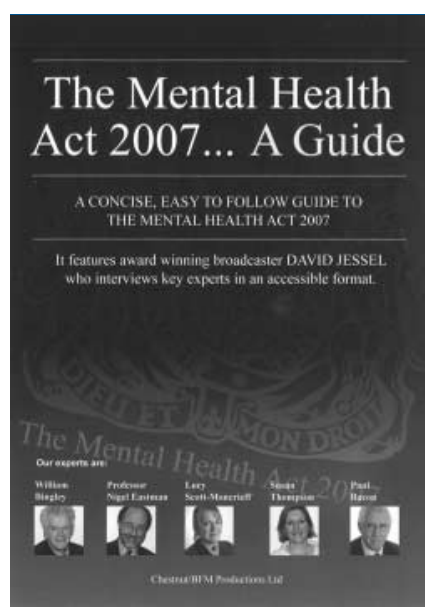

\section{The Mental Health Act} 2007 ... A Guide (DVD)

By David Jessel,

Maggie Fogarty \& Paul Bacon. Chestnut/BFM Productions. 2008. f92.00

I wish I'd seen this before. Before, that is, reading so many descriptions of what to expect. Before going to so many training events. Before hearing lawyers, doctors, managers, social workers and academics speak on the subject. Information overload, coupled in some instances with a substantial helping of conjecture, is not a healthy combination. Perhaps I overdid it in my enthusiasm to know everything there is to know about the Mental Health Act 2007. I should, therefore, confess. I am one of those people, one of those psychiatrists what's more, who find mental health law interesting, fascinating even. And I believe it's important to know it, if we are not to do our patients, ourselves and others a disservice. So this DVD would have been of even greater value had I known of it sooner. For it is what it says it is, 'a concise, easy-to-follow guide to the Mental Health Act 2007'. It is well-structured, to mirror the changes, clear and uncluttered, which is what one would expect given the five experts whose interviews with David Jessell constitute the vast majority of the material and who include William Bingley, Nigel Eastman and Lucy Scott-Moncrieff.

The material is broken down into eight parts, each focusing on a particular area of the new Act. It is well-edited and easy to follow and use. Each section can be viewed, then paused or played again. Questions posed are to the point and get at the essence of the appropriate subject. The information is factual and the contributors avoid speculation as to what the possible effects of the changes might be.

The running time is 50 minutes. The disc comes accompanied by a booklet with a verbatim transcript of the interviews and notes on the relevant sections of the 2007 Act and how these relate to and amend the 1983 legislation. All in all, a good learning resource. It could be argued that it is of less value now that most of the changes have come into force. Equally, though, we are not going to know much more about the new law, how it works and what it changes, until it has been in use for some time and this DVD is an important reference work.

Martin Humphreys University of Birmingham, Hillis Lodge, Hollymoor Way, Northfield, Birmingham B31 5HE, UK. Email: martin.humphreys@bsmhft.nhs.uk

doi: 10.1192/bjp.bp.108.060244

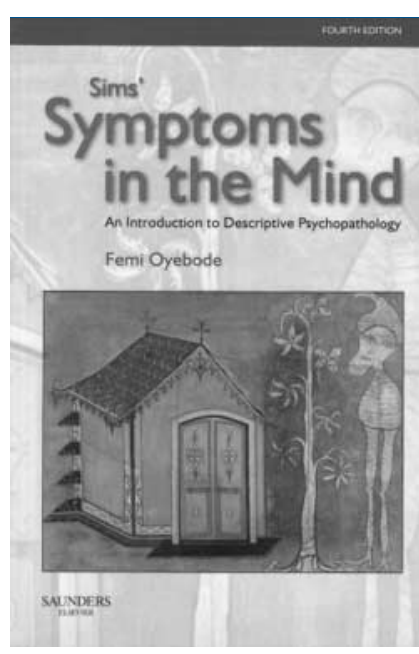

\section{Sims' Symptoms}

in the Mind:

An Introduction

to Descriptive

Psychopathology

(4th edn)

By Femi Oyebode.

Elsevier-Saunders. 2008.

f37.04 (pb). 484pp.

ISBN 9780702028854

This new edition is very welcome. It is an essential tool for trainees and indeed everyone interested in understanding symptoms which we meet in others. Andrew Sims has cause for pride that his book has attained iconic status, as in Gray's Anatomy. Professor Femi Oyebode has done a splendid job in preserving the style that helped to make the earlier editions so attractive. Only 36 pages are added so that middle-age spread has been avoided. The format has benefited from the use of colour and other additions make it more accessible to anyone looking for an answer to a problem in describing and understanding symptoms.

Sims said he aimed the work specifically at the trainee, but hoped others would benefit - the general welcome that successive editions have received show his success. Others of us, like the older Freud (who was said to have a recurrent anxiety dream about failing in the only subject in which he had won a gold medal) may use the book to refresh one's memory. In using it we come across a number of unexpected benefits, including illuminating quotes from past writers, vivid accounts of patients and a remarkable way of putting symptoms in larger contexts; diagrams are helpful. The book continues the tradition of Karl Jaspers 'to be empathic and theoretically neutral' and gives an alternative to popular accounts of dynamics that derive from Freud and others.

Unlike Jaspers who, even in translation, has a forbidding Teutonic density of style, Sims and his editor Oyebode have preserved the approachable, compulsively readable style that may show, in itself, how you can preserve the content even when the form is changed.

Reading this book again reminded me of how Anselm (an 11th-century Archbishop of Canterbury) wrote about his 'delight in understanding. This book will help many readers to enjoy such a delight instead of being alarmed and frightened by some of the more difficult concepts in psychopathology. If they read it carefully, some of the empathic approach is sure to rub off. I sometimes feel psychiatry is threatened by the approach that ticks boxes and seeks refuge in a team. I am glad that books on compassion are now being published: such a spirit seems to me to give this iconic book an added texture. I wish it as much success in psychiatry's troubled future as it has had in the past.

Gaius Davies Emeritus Consultant Psychiatrist, correspondence c/o British Journal of Psychiatry, Royal College of Psychiatrists, 17 Belgrave Square, London SW1X 8PG, UK. Email: bjp@rcpsych.ac.uk

doi: 10.1192/bjp.bp.108.061689 